\title{
Synthesis, insecticidal, and antibacterial activities of novel neonicotinoid analogs with dihydropyridine
}

\author{
Yinju He ${ }^{1,2}$, Deyu Hu${ }^{1,2}$, Mingming L Lv ${ }^{1,2}$, Linhong Jin ${ }^{1,2}$, Jian Wu ${ }^{1,2}$, Song Zeng ${ }^{1,2}$, Song Yang ${ }^{1,2}$ and Baoan Song ${ }^{1,2^{*}}$
}

\begin{abstract}
Background: Nilaparvata lugens, a major pest in rice-growing areas, is extremely difficult to manage. Neonicotinoids have increasingly been used in crop protection and animal health care against N. lugens. To discover new bioactive molecules and pesticides, we combined the active structure of cyanoacrylates, aromatic aldehydes, and substituted pyridyl (thiazolyl) methyl-2-substituted-methylidene-imidazolidine derivatives for the design and synthesis of a series of novel neonicotinoid analogs with dihydropyridine.

Results: A series of neonicotinoid analogs with dihydropyridine were synthesized. Their structures were characterized by $I R,{ }^{1} \mathrm{H} N \mathrm{NMR},{ }^{13} \mathrm{C} N \mathrm{NR}$, and elemental analysis and their insecticidal and antibacterial activities were assessed. Preliminary biological activity tests showed that all of the title compounds feature insecticidal activities against $\mathrm{N}$. lugens at $500 \mathrm{mg} / \mathrm{L}$. Moreover, some compounds showed promising antibacterial activities against Pseudomonas solanacearum (e.g., Tobacco bacterial wilt and Tomato bacterial wilt) at a dose of $200 \mathrm{mg} / \mathrm{L}$.

Conclusion: A synthetic route to obtain neonicotinoid analogs with dihydropyridine by the reaction of intermediates 2 (pyridyl (thiazolyl) methyl-2-substituted-methyl-ideneimidazolidine) and intermediates 1 (cyanoacrylates) and different aromatic aldehydes in acetonitrile under reflux conditions is presented. The effects of different solvents, bases, and reaction time on the reaction of $3 a$ were investigated. The results of this study suggest that neonicotinoid analogs with dihydropyridine could cause N. lugens death and restrain $P$. solanacearum growth.
\end{abstract}

\section{Background}

Rice is distributed in all of the continents worldwide. A considerable amount of money has been invested to prevent yield losses caused by Nilaparvata lugens each year. $N$. lugens has become a major pest in rice-growing areas and extensive studies have been carried out to develop several control programs against the insect. Imidacloprid is probably the most widely used insecticide against $N$. lugens. However, it is relatively toxic toward mammals and aquatic species, such as birds, bees, and silkworms. Imidacloprid is obtained by structural modification of the lead compound CH-IMI [1-3]. Given that $\mathrm{CH}-\mathrm{IMI}$ has been reported as a potential new insecticide, a series of neonicotinoid insecticides that use

\footnotetext{
* Correspondence: basong@gzu.edu

${ }^{1}$ State Key Laboratory Breeding Base of Green Pesticide and Agricultural Bioengineering, Key Laboratory of Green Pesticide and Agricultural Bioengineering, Ministry of Education, Guizhou University, Guiyang, China ${ }^{2}$ Research and Development Center for Fine Chemicals, Guizhou University, Guiyang 550025, China
}

$\mathrm{CH}-\mathrm{IMI}$ as a basic unit have been rapidly developed in recent years. These insecticides possess novel structures and various modes of action compared with traditional insecticides, including hexahydronitroimidazopyrimidines [4-6], some of which are shown as compounds I to IV (Figure 1) [7-12]. Neonicotinoid insecticides are known to act agonistically and show high selectivity to insect nicotinic acetylcholine receptors; they are also relatively safe toward mammals and aquatic species [13-15]. Neonicotinoids are increasingly used in crop protection and animal health care against a broad spectrum of sucking and biting insects [16-20]. However, the excessive and frequent use of neonicotinoid pesticides causes significant increases in pest resistance.

Neonicotinoid insecticides have many mutual molecular characteristics. The presence of a strong electron-withdrawing pharmacophoric group, such as $\mathrm{CN}$ or $\mathrm{NO}_{2}$, is an essential structural characteristic of these insecticides $[21,22]$. Amide derivatives have shown promising insecti-
(C) Chemistry Central

(C) 2013 He et al.; licensee Chemistry Central Ltd. This is an Open Access article distributed under the terms of the Creative Commons Attribution License (http://creativecommons.org/licenses/by/2.0), which permits unrestricted use, distribution, and reproduction in any medium, provided the original work is properly cited. 
<smiles>[R10]C1CC([R10])N2CCN(Cc3ccc(Cl)nc3)C2=C1[N+](=O)[O-]</smiles><smiles>[R]Oc1cn(C)c(N(CC)Cc2ccc(Cl)nc2)c1[N+](=O)[O-]</smiles>

Figure 1 Commercialized neonicotinoid insecticides and active compounds.

cidal activity [23-26]. In our previous work, we synthesized cyanomethylene heterocycles, such as compound V (Figure 1), by the reaction of different cyanoacrylate derivatives with $N$-((6-chloropyridin-3-yl) methyl) ethane-1, 2-diamine, yielding several compounds that showed good insecticidal activity [27]. The elementary structure of $\mathrm{CH}$ IMI was maintained and the cyclization gain pyridine ring involved an amide moiety. Based on these results, neonicotinoid analogs with dihydropyridine were prepared (Scheme 1). All of the compounds were characterized by IR, ${ }^{1} \mathrm{H}$ NMR, ${ }^{13} \mathrm{C}$ NMR, and elemental analysis. Preliminary biological evaluations revealed that most of the compounds exhibit insecticidal activity against $N$. lugens. Compounds 3a, 3c, and 3e exhibited $\geq 90.3 \%$ activity at a dose of $500 \mathrm{mg} / \mathrm{L}$. Moreover, some of the compounds showed promising antibacterial activities against Pseudomonas solanacearum. Compound 3a showed particularly potent antibacterial activity that reached $88.1 \%$ against tomato bacterial wilt at a dose of $200 \mathrm{mg} / \mathrm{L}$.

\section{Results and discussion}

\section{Synthesis}

Scheme 1 demonstrates the synthetic route to the title compounds (Additional file 1). Intermediates 1 (cyanoacrylates) were prepared by the reaction of cyanoacetic acid with arylamine. Cyanoacrylates with different aromatic aldehydes in acetonitrile were then refluxed to yield to intermediates 2 (pyridyl (thiazolyl) methyl-2-substitutedmethyl-ideneimidazolidine derivatives). The title compounds $\mathbf{3}$ were prepared by cyclization of intermediates $\mathbf{2}$ with cyanoacrylates and different aromatic aldehydes in acetonitrile under reflux conditions. To optimize the reaction conditions of compounds $\mathbf{3}$, the synthesis of $\mathbf{3 a}$ was carried out in several experiments. The effects of different solvents, bases, and reaction time on the reaction were investigated, the results of which are shown in Table 1. When acetonitrile, 1,4-dioxane, DMF, and ethanol were used under reflux conditions in the presence of triethylamne for $24 \mathrm{~h}$, the yields of $3 \mathbf{a}$ were $35.8 \%, 12.6 \%$,

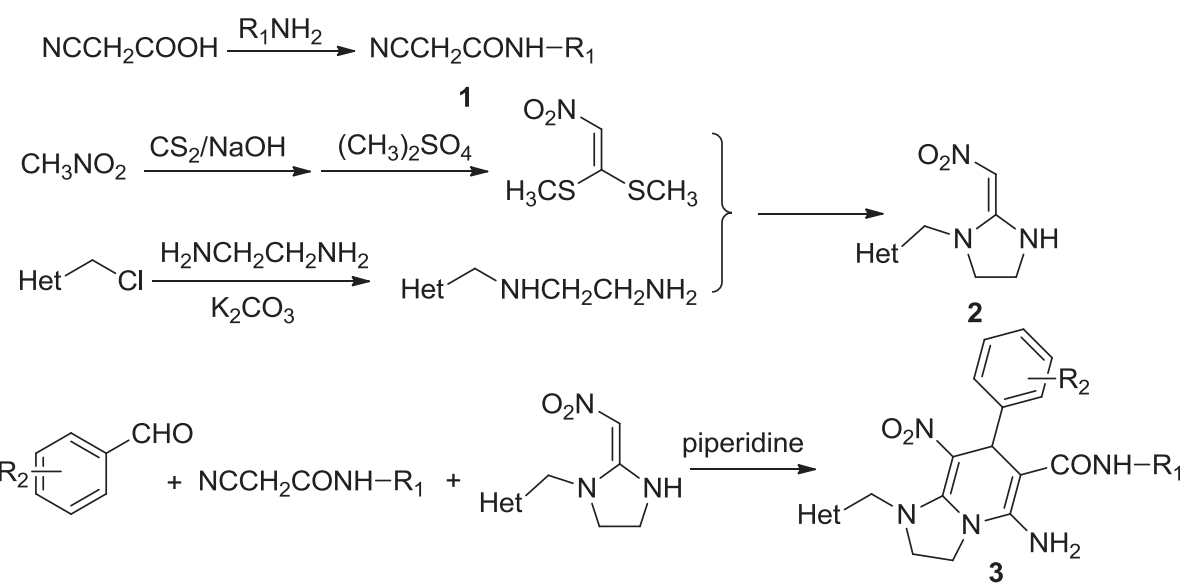

Scheme 1 Synthetic route to the title compounds 3. 
Table 1 Yields of 3a at different reaction conditions

\begin{tabular}{ccccc}
\hline No. & Solvent & Base & Time $(\mathbf{h})$ & Yield (\%) \\
\hline 1 & ethanol & triethylamine & 24 & 15.1 \\
2 & acetonitrile & triethylamine & 24 & 35.8 \\
3 & DMF & triethylamine & 24 & 25.4 \\
4 & 1,4-dioxane & triethylamine & 24 & 12.6 \\
5 & acetonitrile & $\mathrm{K}_{2} \mathrm{CO}_{3}$ & 24 & 33.2 \\
6 & acetonitrile & pyridine & 24 & 20.1 \\
7 & acetonitrile & piperidine & 24 & 51.4 \\
8 & acetonitrile & piperidine & 18 & 56.6 \\
9 & acetonitrile & piperidine & 12 & 42.2 \\
\hline
\end{tabular}

$25.4 \%$, and $15.1 \%$, respectively (Table 1, entries $1-4$ ). Using acetonitrile as an organic solvent, the synthesis of $\mathbf{3 a}$ was found to proceed smoothly. At reaction times of 12, 18, and $24 \mathrm{~h}, 3 \mathrm{a}$ was obtained in yields of $42.2 \%, 56.6 \%$, and $51.4 \%$, respectively, using piperidine as a base (Table 1 , entries 7-9). However, at reaction times ranging from 18 to $24 \mathrm{~h}$, no further improvements were obtained. The synthesis of 3a using different bases (including an inorganic base, such as $\mathrm{K}_{2} \mathrm{CO}_{3}$, and organic bases, such as triethylamine, pyridine, and piperidine) was investigated. The results demonstrated that the presence of piperidine could accelerate the cyclization reaction (Table 1, entires $5-7$ ). The best yield was obtained when intermediates 2 were treated with intermediates $\mathbf{1}$ and aromatic aldehydes in the presence of piperidine under stirring for $18 \mathrm{~h}$ with acetonitrile as the solvent by reflux. The yield of compounds $\mathbf{3 a}$ to $\mathbf{3 l}$ under these reaction conditions are listed in Table 2 (Additional file 2).

All of the synthesized compounds 3 were characterized on the basis of their spectroscopic data. IR absorption bands ranging were assigned as follows: 3425 to $3180 \mathrm{~cm}^{-1}(-\mathrm{CONH}), 3000$ to $2910 \mathrm{~cm}^{-1}\left(-\mathrm{CH}_{2} \mathrm{CH}_{2}\right)$, 1660 to $1630 \mathrm{~cm}^{-1}$ (-CO), 1560 to $1505 \mathrm{~cm}^{-1}\left(-\mathrm{NH}_{2}\right)$, 1368 to $1339 \mathrm{~cm}^{-1}\left(-\mathrm{NO}_{2}\right), 1220$ to $1240 \mathrm{~cm}^{-1}$ (Ar-H), and 1100 to $1152 \mathrm{~cm}^{-1}\left(=\mathrm{CH}\left(=\mathrm{CH}-\mathrm{NO}_{2}\right)\right)$. In the ${ }^{1} \mathrm{H}$ NMR spectra of 3a, the -CONH fragment displayed a singlet with a chemical shift of $\delta 8.21 \mathrm{ppm}$ while the $\mathrm{CH}_{2} \mathrm{CH}_{2}$ fragment in the imidazolidine moiety displayed a multiplet with chemical shifts ranging from $\delta 3.89$ $\mathrm{ppm}$ to $4.29 \mathrm{ppm}$. Protons of $-\mathrm{CH}_{2}$ linking with a pyridine or thiazole ring were shifted downfield, ranging from $\delta 4.64 \mathrm{ppm}$ to $4.77 \mathrm{ppm}$ as a multiplet. The $-\mathrm{CH}$ fragment linking with $\mathrm{C}$ and $\mathrm{N}$ in the pyridine ring was shifted downfield to $\delta 7.47 \mathrm{ppm}$. The $-\mathrm{NH}_{2}$ fragment displayed a singlet with chemical shifts ranging from $\delta$ $7.66 \mathrm{ppm}$ to $7.69 \mathrm{ppm}$.

\section{Biological activity and structure-activity relationship}

The insecticidal activity of the title compounds was tested against $N$. lugens and the bioassay results were given in Table 3. The results of initial screening showed that $500 \mathrm{mg} / \mathrm{L}$ of the newly synthesized compounds have moderate to potent activities. The mortality rates of $\mathbf{3 a}$ ( $R_{1}$ is benzyl, $R_{2}$ is $H$, and het is 6-chloro-pyridin-3-yl), 3c $\left(R_{1}\right.$ is 4-methylbenzyl, $R_{2}$ is $H$, and het is 6-chloropyridin-3-yl), and $3 \mathbf{e}\left(\mathrm{R}_{1}\right.$ is 4-oxethyl, $\mathrm{R}_{2}$ is $\mathrm{H}$, and het is 6-chloro-pyridin-3-yl) against $N$. lugens were $91.2 \%$, $92.0 \%$, and $90.3 \%$, respectively, slightly lower than those of pymetrozine and nitenpyram (100\%). Compounds 3d, 3f, $\mathbf{3 i}$, and $3 \mathbf{l}$ at a dose of $500 \mathrm{mg} / \mathrm{L}$ exhibited moderate activities against $N$. lugens, with mortality rates of $53.3 \%$, $66.0 \%, 51.8 \%$, and $56.4 \%$, respectively. As shown in Table 4, the antibacterial activities of compounds 3 were tested in vitro against Ralstonia solanacearum. Some of the title compounds at $200 \mathrm{mg} / \mathrm{L}$ indicated moderate to

Table 2 Structure, yield and elemental analysis data for title compounds 3a-3I

\begin{tabular}{|c|c|c|c|c|c|c|c|}
\hline \multirow[t]{2}{*}{ NO. } & \multirow[t]{2}{*}{$\mathbf{R}_{1}$} & \multirow[t]{2}{*}{$\mathbf{R}_{2}$} & \multirow[t]{2}{*}{ Het } & \multirow[t]{2}{*}{ Yield (\%) } & \multicolumn{3}{|c|}{ Elemental Analysis (Calcd./Found) } \\
\hline & & & & & C & $\mathbf{H}$ & $\mathbf{N}$ \\
\hline $3 a$ & benzyl & $\mathrm{H}$ & 6-chloro-pyridin-3-yl & 56.3 & $62.73 / 62.39$ & $4.87 / 4.81$ & $16.26 / 16.44$ \\
\hline $3 b$ & benzyl & $4-\mathrm{OH}$ & 6-chloro-pyridin-3-yl & 46.6 & $60.84 / 60.56$ & $4.73 / 4.45$ & $15.77 / 15.53$ \\
\hline $3 c$ & 4-Mebenzyl & $\mathrm{H}$ & 6-chloro-pyridin-3-yl & 61.9 & $62.73 / 62.53$ & $4.87 / 4.82$ & $16.26 / 15.99$ \\
\hline $3 d$ & 4-Mebenzyl & $4-\mathrm{OH}$ & 6-chloro-pyridin-3-yl & 68.2 & $60.84 / 61.03$ & $4.73 / 4.46$ & $15.77 / 15.68$ \\
\hline $3 e$ & $4-\mathrm{EtOC}_{6} \mathrm{H}_{4}$ & $\mathrm{H}$ & 6-chloro-pyridin-3-yl & 52.1 & $61.48 / 61.81$ & $4.98 / 4.66$ & 15.36/15.61 \\
\hline $3 f$ & $4-\mathrm{EtOC}_{6} \mathrm{H}_{4}$ & $4-\mathrm{OH}$ & 6-chloro-pyridin-3-yl & 55.4 & $59.73 / 59.45$ & $4.83 / 4.61$ & $14.93 / 15.24$ \\
\hline $3 g$ & $2-\mathrm{NO}_{2} \mathrm{C}_{6} \mathrm{H}_{4}$ & $\mathrm{H}$ & 6-chloro-pyridin-3-yl & 34.6 & $55.37 / 54.99$ & $3.93 / 4.12$ & $17.39 / 17.46$ \\
\hline $3 h$ & $2-\mathrm{NO}_{2} \mathrm{C}_{6} \mathrm{H}_{4}$ & $4-\mathrm{OH}$ & 6-chloro-pyridin-3-yl & 39.8 & $55.37 / 54.99$ & $3.93 / 4.12$ & $17.39 / 17.46$ \\
\hline $3 \mathbf{i}$ & benzyl & $\mathrm{H}$ & 2-chloro-thiazol-5-yl & 41.1 & $57.41 / 57.23$ & $4.43 / 4.70$ & $16.07 / 16.15$ \\
\hline $3 \mathbf{j}$ & benzyl & $4-\mathrm{OH}$ & 2-chloro-thiazol-5-yl & 45.5 & $55.71 / 55.42$ & $4.30 / 4.49$ & $15.59 / 15.26$ \\
\hline $3 k$ & $4-\mathrm{MeC}_{6} \mathrm{H}_{4}$ & $\mathrm{H}$ & 2-chloro-thiazol-5-yl & 43.6 & $57.41 / 57.64$ & $4.43 / 4.65$ & $16.07 / 16.36$ \\
\hline 31 & $4-\mathrm{MeC}_{6} \mathrm{H}_{4}$ & $4-\mathrm{OH}$ & 2-chloro-thiazol-5-yl & 49.0 & $55.71 / 55.94$ & $4.30 / 4.16$ & $15.59 / 15.91$ \\
\hline
\end{tabular}


Table 3 Insecticidal activities of compounds $3 a$ to 3 I against Nilaparvata lugens

\begin{tabular}{ccc}
\hline Compounds. & Concentration (mg/L) & Mortality (\%) \\
\hline 3a & 500 & 91.2 \\
3b & 500 & 45.7 \\
3c & 500 & 92.0 \\
3d & 500 & 53.3 \\
3e & 500 & 90.3 \\
3f & 500 & 66.0 \\
3g & 500 & 48.9 \\
3h & 500 & 46.2 \\
3i & 500 & 51.8 \\
3j & 500 & 34.1 \\
3k & 500 & 31.0 \\
3l & 500 & 56.4 \\
Pymetrozine & 500 & 100.0 \\
Nitenpyram & 500 & 100.0 \\
Ck & $/$ & 0.0 \\
\hline
\end{tabular}

good activity against tobacco bacterial wilt and tomato bacterial wilt. When $R_{1}$ is benzyl, $R_{2}$ is $H$, and het is 6-chloro-pyridin-3-yl, compound 3a showed inhibitory rates of $72.0 \%$ and $88.1 \%$ against tobacco bacterial wilt and tomato bacterial wilt, respectively, slightly lower than those of the reference (100\%). The inhibitory rates of compounds $3 \mathbf{f}$ and $3 \mathbf{h}$ at a dose of $200 \mathrm{mg} / \mathrm{L}$ were $62.3 \%$ and $65.6 \%$, respectively. Compounds $3 \mathbf{b}, 3 \mathbf{3 c}, \mathbf{3 d}$,

Table 4 The antibacterial activity of compounds 3 a to $3 \mathrm{I}$, Kocide against Tobacco bacterial wilt and Tomato bacterial wilt at $200 \mathrm{mg} / \mathrm{L}$

\begin{tabular}{ccc}
\hline Compounds. & Tobacco bacterial wilt (\%) & Tomato bacterial wilt (\%) \\
\hline 3a & 72.0 & 88.1 \\
3b & 45.8 & 45.3 \\
3c & 52.6 & 42.1 \\
$\mathbf{3 d}$ & 49.1 & 49.2 \\
$\mathbf{3 e}$ & 56.3 & 46.3 \\
$\mathbf{3 f}$ & 43.0 & 62.3 \\
$\mathbf{3 g}$ & 77.3 & 43.6 \\
$\mathbf{3 h}$ & 15.6 & 65.6 \\
$\mathbf{3 i}$ & 40.2 & 45.5 \\
$\mathbf{3 j}$ & 12.4 & 12.0 \\
$\mathbf{3 k}$ & 47.3 & 43.6 \\
$\mathbf{3 l}$ & 14.9 & 26.1 \\
Kocide $^{\circledR} \mathbf{3 0 0 0}$ & 100.0 & 100.0 \\
$\left(\mathbf{C u}(\mathbf{O H})_{\mathbf{2}}\right)$ & & \\
\hline
\end{tabular}

3e, 3g, 3i , and 3k at a dose of $200 \mathrm{mg} / \mathrm{L}$ exhibited moderate activities against tomato bacterial wilt, with inhibitory rates of $45.3 \%, 42.1 \%, 49.2 \%, 46.3 \%, 43.6 \%, 45.5 \%$, and $43.6 \%$, respectively. Through the results of the activities, the regularity of structure-activity relationship were not observed that compounds demonstrated good activities with either electron-with drawing or electrondonating groups. Nevertheless, the further study is underway, except to gain the law of the structure-activity relationship.

\section{Experimental \\ Chemistry}

Melting points were determined with an X-4 digital micro-melting point meter display and are reported uncorrected. ${ }^{1} \mathrm{H}$ NMR spectra and ${ }^{13} \mathrm{C}$ NMR spectra were recorded with a JEOL ECX 500 NMR spectrometer at room temperature with TMS as the internal reference and DMSO- $d_{6}$ as the solvent. IR spectra were recorded in $\mathrm{KBr}$ on a Bruker VECTOR 22 spectrometer. Elemental analyses were performed with an Elemental Vario-III $\mathrm{CHN}$ analyzer. Analytical TLC was performed on silica gel GF254. Column chromatographic purification was carried out using silica gel. All of the reagents and reactants were purchased from commercial suppliers and of analytical reagent grade. Intermediates $\mathbf{1}$ and $\mathbf{2}$ were prepared according to the methods described in literature [1-3,27].

Intermediates $\mathbf{1}(1.25 \mathrm{mmol})$, aromatic aldehyde (1.25 $\mathrm{mmol})$, and piperidine $(0.10 \mathrm{mmol})$ in acetonitrile $(5 \mathrm{~mL})$ were refluxed with stirring for $8 \mathrm{~h}$. Solutions of intermediates $2(1.00 \mathrm{mmol})$ in acetonitrile $(2 \mathrm{~mL})$ were then added dropwise to the mixture of intermediates $\mathbf{1}$. The resulting solution was refluxed with stirring for $10 \mathrm{~h}$ until the reaction was completed. The progress of the reaction was monitored by TLC and dichloromethane/methanol was used as an eluent. The filtrate was evaporated and the residue was purified by column chromatography on silica gel (dichloromethane:methanol $(\mathrm{v} / \mathrm{v})=10-20: 1)$, yielding the corresponding products 3 . Experimental details and spectroscopic data of intermediates $\mathbf{1}$ and $\mathbf{2}$ and the title compounds $\mathbf{3 a}-\mathbf{3 l}$ are listed in Additional file 3.

\section{Insecticidal biological assay}

The insecticidal activities of the compounds against $N$. lugens were evaluated using the reported procedure $[27,28]$. The title compounds under investigation were dissolved in $200 \mu \mathrm{L}$ of DMSO and diluted with water containing Tween-20 $(0.1 \mathrm{mg} / \mathrm{L})$ to a final concentration of $500 \mathrm{mg} / \mathrm{L}$. About 15 rice plants $(\sim 10 \mathrm{~cm}$ length) with roots dipped for $10 \mathrm{~s}$ in the compound solutions were tested. The plants were air-dried and their roots were wrapped in moist cotton. The plants were subsequently placed into a tumbler to which 10 third instar N. lugens 
were introduced. The treated insects were maintained at a temperature of $27^{\circ} \mathrm{C} \pm 1^{\circ} \mathrm{C}$. Three replicates were performed for each compound. Water containing Tween-20 $(0.1 \mathrm{mg} / \mathrm{L})$ and DMSO was used as the control and mortality rates were assessed after $72 \mathrm{~h}$. The mortality rates were calculated using the following equation:

$$
\begin{aligned}
& P_{1}=[K / N] \times 100 \% \\
& P_{2}=\left[\left(P_{t}-P_{0}\right) /\left(1-P_{0}\right)\right] \times 100 \%
\end{aligned}
$$

$P_{1}$ : the mortality rate (\%), $K$ : the number of dead insects, and $N$ : the total number of insects; $P_{\mathrm{o}}$ : the blank control mortality rate (\%), $P_{2}$ : the corrected mortality rate $(\%)$, and $P_{t}$ : the treatment mortality.

\section{Antibacterial biological assay}

The antibacterial activities of all of the title compounds against tobacco bacterial wilt and tomato bacterial wilt were evaluated by a turbidimeter test [29]. Kocide 3000 was used as the positive control. The compounds were dissolved in $150 \mu \mathrm{L}$ of DMSO, diluted with water containing Tween-20 $(0.1 \%$, Tween-20: water, $\mathrm{v} / \mathrm{v})$ to a final concentration of $200 \mathrm{mg} / \mathrm{L}$, and then added to nutrient broth (NB) liquid medium in $5 \mathrm{~mL}$ tubes. About $40 \mu \mathrm{L}$ of NB liquid medium containing the solanacearum pathogen was individually added to these tubes. Shaking at $30^{\circ} \mathrm{C}$ and $180 \mathrm{rpm}$ for $48 \mathrm{~h}$ followed. The relative inhibition rate of the circle mycelium compared with the blank assay was calculated using the following equation.

$$
\text { Relative inhibitory rate }(\%)=\left[\left(A_{0}-A_{1}\right) / A_{0}\right] \times 100 \%
$$

$A_{0}$ : Corrected OD values of the control medium of bacilli.

$A_{1}$ : Corrected OD values of the medium of toxic.

\section{Conclusion}

A series of novel neonicotinoid analogs with dihydropyridine were designed and synthesized by the cyclization condensation reaction of intermediates $\mathbf{1}$ with different aromatic aldehydes and intermediates 2 in acetonitrile under reflux conditions. The effects of different solvents, bases, and reaction time on the reaction of 3a were investigated, and the best yield was obtained when intermediates 2 were treated with intermediates 1 and aromatic aldehydes in the presence of piperidine under stirring for $18 \mathrm{~h}$ with acetonitrile as the solvent by reflux. Antibacterial tests showed that some of the synthesized compounds possessed moderate to high activities against tobacco bacterial wilt and tomato bacterial wilt. Compound 3a revealed favorable activity against tomato bacterial wilt in vitro compared with the commercial bactericide Kocide 3000. Most of the compounds exhibited potent insecticidal activity against nilaparvata lugens. Compounds 3a, 3c, and 3e showed higher insecticidal activities than the other compounds. These primary results are promising and beneficial for further research on the development of new and more effective bactericides and pesticides. Further design studies and biological assessments of these compounds are ongoing in our laboratory.

\section{Additional files}

Additional file 1: Synthetic route to target compounds 3a-3l.

Synthetic route to novel neonicotinoid analogs with dihydropyridine from intermediates 2 .

Additional file 2: Yield and elemental analysis data of the title compounds $\mathbf{3 a}-\mathbf{3 l}$. This file contains structural, yield, and elemental analyses data of the title compounds $\mathbf{3 a} \mathbf{a} \mathbf{3}$.

Additional file 3: Experimental details and data of the title compounds $\mathbf{3 a}-\mathbf{3} \mathbf{3}$. This file includes the experimental procedures and spectroscopic data of intermediates $\mathbf{1}$ and $\mathbf{2}$ and title compounds $\mathbf{3 a}-\mathbf{3} \mathbf{I}$, as well as copies of IR, ${ }^{1} \mathrm{H}$ NMR and ${ }^{13} \mathrm{C}$ NMR.

\section{Competing interests}

The authors declare that they have no competing interests.

\section{Authors' contributions}

The current study is the outcome of constructive discussions between BAS, DYH, and JW, who offered the necessary guidance to YJH to carry out the synthesis and characterization experiments. YJH was involved in drafting the manuscript. MML performed the insecticidal activity tests and JW carried out the ${ }^{1} \mathrm{H}$ NMR, ${ }^{13} \mathrm{C}$ NMR. LHJ, SY and SZ carried out the elemental analyses. BAS and DYH were involved in revising the manuscript. All authors have read and approve of the final manuscript.

\section{Acknowledgments}

This work was supported by the National Key Program for Basic Research (Grant No. 2010CB 126105), the Key Technologies R\&D Program (Grant No. 2011BAE06B05-6), and the National Natural Science Foundation of China (Grant No. 21162004).

Received: 3 February 2013 Accepted: 1 April 2013 Published: 26 April 2013

\section{References}

1. Tomizawa M, Yamamoto I: Structure-activity relationships of nicotinoids and imidacloprid analogs. J Pestic Sci 1993, 18:91-98.

2. Kagabu S, Moriya K, Shibuya K, Hattori Y, Tsuboi S, Shiokawa K: 1-(6-Haloni- cotinyl)-2-nitromethylene-imidazolidines as potential new insecticides. Biosci Biotechnol Biochem 1992, 56:362-363.

3. Liu MY, Lanford J, Casida JE: Relevance of [3H]imidacloprid binding site in house fly head acetylcholine receptor to insecticidal activity of 2-nitromethylene and 2-nitroimino-imidazolidines. Pestic Biochem Physiol 1993, 46:200-206.

4. Kishida H, Sakamoto N, Umeda K, Fujimoto H: Preparation of nitropyrimidine derivatives as insecticides. Chem Abstr 1992, 118:22251. JP, 04173788[P]. 1992-06-22.

5. Kruger BW, Uhr H, Kanellakopulos J, Gesing ERF, Wolf H, Turberg A, Mencke N, Erdelen C, Wachendorff-Neumann U, Hartwig J: Substituierte 1,2,3,4-tetrahydro- 5-nitro-pyrimidines. Chem Abstr 1992, 124:8836. DE, 4401635AI[P]. 1995-07-27.

6. Latli B, Tomizawa M, Casida JE: Synthesis of a Novel $\left[{ }^{125} \mid\right]$ Neonicotinoid photoaffinity probe for the Drosophila nicotinic acetylcholine receptor. Bioconjugate Chem 1997, 8:7-14.

7. Tian ZZ, Shao XS, Li Z, Qian XH, Huang QC: Synthesis, insecticidal activity, and QSAR of novel nitromethylene neonicotinoids with 
tetrahydropyridine fixed cis Configuration and Exo-Ring ether modification. J Agric Food Chem 2007, 55:2288-2292.

8. Zhang WW, Yang XB, Chen WD, Xu XY, Li L, Zhai HB, Li Z: Design, multicomponent synthesis, and bioactivities of novel neonicotinoid analogues with 1, 4-dihydropyridine scaffold. J Agric Food Chem 2010, $58: 2741-2745$

9. Sun CW, Xu X, Xu YH, Yan DR, Fang T, Liu TY: Synthesis, insecticidal activity, and molecular docking studies of nitenpyram analogues with a flexible ester arm anchored on tetrahydropyrimidine ring. J Agric Food Chem 2011, 59:4828-4835.

10. Ye ZJ, Xia S, Shao XS, Cheng JG, Xu XY, Xu ZP, Li Z, Qian XH: Design, synthesis, crystal structure snalysis, and insecticidal evaluation of phenylazoneonicotinoids. J Agric Food Chem 2011, 59:10615-10623.

11. Sun CW, Fang T, Wang J, Hao ZB, Nan SB: Synthesis, insecticidal activity, crystal structure, and molecular docking studies of nitenpyram analogues with an $\omega$-Hydroxyalkyl ester arm anchored on the tetrahydropyrimidine eing. J Agric Food Chem 2012, 60:9553-9561.

12. Ye ZJ, Shi LN, Shao XS, XU XY, Xu ZP, Li Z: Pyrrole and dihydropyrrole fused neonicotinoids: Design, eynthesis, and insecticidal evaluation. J Agric Food Chem 2013, 61:312-319.

13. Mori Ke Okumoto T, Kawahara N, Ozoe Y: Interaction of dinotefuran and its analogues with nicotinic acetylcholine receptors of cockroach nerve cords. Pest Manag Sci 2002, 58:190-196.

14. Bai DL, Lummis SCR, Leicht W, Breer H, Sattelle DB: Actions of imidacloprid and a aelated nitromet hylene on cholinergic receptors of an identified insect motor newone*. Pestic Sci 1991, 33:197-204.

15. Shao XS, Li Z, Qian XH, Xu XY: Design, synthesis, and insecticidal activities of novel nnalogues of neonicotinoids: Replacement of nitromethylene with nitroconjugated system. J Agric Food Chem 2009, 57:951-957.

16. Talley $\Pi$, Harel M, Hibbs RE, Radic Z, Tomizawa M, Casida JE, Taylor P. Atomic interactions of neonicotinoid agonists with AChBP: Molecular recognition of the distinctive electronegative pharmacophore. Proc Nat Acad Sci USA 2008, 105:7606-7611.

17. Tomizawa M, Maltby D, Talley T, DurKin KA, Medzihradszky KF, Burlingame AL, Taylor P, Casida JE: Atypical nicotinic agonist bound conformations conferring subtype selectivity. Proc Natl Acad Sci USA 2008, 105:1728-1732.

18. Ohno I, Tomizawa M, Durkin KA, Naruse $Y$, Casida JE, Kagabu S: Molecular features of neonicotinoid pharmacophore variants interacting with the insect nicotinic receptor. Chem Res Toxicol 2009, 22:476-482.

19. Tomizawa M, Casida JE: Molecular recognition of neonicotinoid insecticides: The determinants of life or death. Acc Chem Res 2009, 42:260-269

20. Jeschke P, Nauen R: Review neonicotinoids from zero to hero in insecticide chemistry. Pest Manag Sci 2008, 64:1084-1098.

21. Ohno I, Tomizawa M, Aoshima A, Kumazawa S, Kagabu S: Trifluoroacetyl neonicotinoid insecticides with enhanced hydrophobicity and effectiveness. J Agric Food Chem 2010, 58:4999-5003

22. Tomizawa M, Lee DL, Casida JE: Neonicotinoid insecticides: Molecular features conferring selectivity for insect versus mammalian nicotinic receptors. J Agric Food Chem 2000, 48:6016-6024.

23. Stevenson TM, Stevenson M: Preparation of insecticidal amides with nitrogen-containing benzo-fused bicyclic ring systems. Chem Abstr 2003, 140:14039. JP, 2005529937[P]. 2003-12-18.

24. Yoshida K, Wakita T, Katsuta H, Kai A, Chiba Y, Takahashi K, Kato H, Kawahara N, Nomura M, Daido H, Maki J, Banba S, Hiba Y: Preparation of 3-benozylaminobenzamide derivatives and related amides derivatives as insecticides. Chem Abstr 2005, 143:211723. EP, 1714958[P]. 2005-08-11.

25. Yoshida K, Kobayashi Y, Nomura M, Kawahara N, Daido H, Inomata S, Kei Y: Preparation of benzamide derivatives as pesticides. Chem Abstr 2006, 146:100428. EP, 1916236[P]. 2006-06-20.

26. Wakita T, Daido H, Kai A, Kawahara N, Yoshida K: Preparation of benzamides and related compounds as insecticides. Chem Abstr 2007, 146:441501. JP, 2007099761 [P]. 2007-04-19.
27. Wu J, Yang S, Song BA, Bhadury PS, Hu DY, Zeng S, Xie HP: Synthesis and insecticidal activities of novel neonicotinoid analogs bearing an 2-cyanoacrylates containing pyridinyl moiety. J Heterocycl Chem 2011, 48(1):901-906

28. Wang YH, Chen J, Zhu YC, Ma CY, Huang Y, Shen JL: Susceptibility to neonicotinoids and risk of resistance development in the brown planthopper, Nilaparvata lugens (Stal) (Homoptera: Delphacidae). J Pest Manag Sci 2008, 64(12):1278-1284.

29. Wu J, Kang SH, Song BA, Hu DY, He M, Jin LH, Yang S: Synthesis and antibacterial activity against Ralstonia solanacearum for novel hydrazone derivatives containing a pyridine moiety. Chem Cent J 2012, 6:28.

doi:10.1186/1752-153X-7-76

Cite this article as: He et al:: Synthesis, insecticidal, and antibacterial activities of novel neonicotinoid analogs with dihydropyridine. Chemistry Central Journal 2013 7:76.

\section{Publish with ChemistryCentral and every scientist can read your work free of charge \\ "Open access provides opportunities to our colleagues in other parts of the globe, by allowing anyone to view the content free of charge." W. Jeffery Hurst, The Hershey Company. \\ - available free of charge to the entire scientific community \\ - peer reviewed and published immediately upon acceptance \\ - cited in PubMed and archived on PubMed Central \\ - yours - you keep the copyright \\ Submit your manuscript here: \\ http://www.chemistrycentral.com/manuscript/<smiles>c1ccccc1</smiles> \\ Chemistry Central}

